\title{
Prenatal ambient air pollution and maternal depression at 12 months postpartum in the MADRES pregnancy cohort
}

Theresa M. Bastain ${ }^{1 *} \mathbb{D}$, Thomas Chavez ${ }^{1}$, Rima Habre ${ }^{1}$, Ixel Hernandez-Castro ${ }^{1}$, Brendan Grubbs², Claudia M. Toledo-Corral ${ }^{1,3}$, Shohreh F. Farzan ${ }^{1}$, Nathana Lurvey ${ }^{4}$, Deborah Lerner ${ }^{4}$, Sandrah P. Eckel ${ }^{1}$, Fred Lurmann ${ }^{5}$, Isabel Lagomasino ${ }^{6}$ and Carrie Breton ${ }^{1}$

\begin{abstract}
Background: Depression is the leading cause of mental health-related morbidity and affects twice as many women as men. Hispanic/Latina women in the US have unique risk factors for depression and they have lower utilization of mental health care services. Identifying modifiable risk factors for maternal depression, such as ambient air pollution, is an urgent public health priority. We aimed to determine whether prenatal exposure to ambient air pollutants was associated with maternal depression at 12 months after childbirth.

Methods: One hundred eighty predominantly low-income Hispanic/Latina women participating in the ongoing MADRES cohort study in Los Angeles, CA were followed from early pregnancy through 12 months postpartum through a series of phone questionnaires and in-person study visits. Daily prenatal ambient pollutant estimates of nitrogen dioxide $\left(\mathrm{NO}_{2}\right)$, ozone $\left(\mathrm{O}_{3}\right)$, and particulate matter $\left(\mathrm{PM}_{10}\right.$ and $\left.\mathrm{PM}_{2.5}\right)$ were assigned to participant residences using inverse-distance squared spatial interpolation from ambient monitoring data. Exposures were averaged for each trimester and across pregnancy. The primary outcome measure was maternal depression at 12 months postpartum, as reported on the 20-item Center for Epidemiologic Studies-Depression (CES-D) scale. We classified each participant as depressed ( $n=29$ ) or not depressed $(n=151)$ based on the suggested cutoff of 16 or above (possible scores range from 0 to 60) and fitted logistic regression models, adjusting for potential confounders.

Results: We found over a two-fold increased odds of depression at 12 months postpartum associated with second trimester $\mathrm{NO}_{2}$ exposure $(\mathrm{OR}=2.63,95 \% \mathrm{Cl}: 1.41-4.89)$ and pregnancy average $\mathrm{NO}_{2}(\mathrm{OR}=2.04,95 \% \mathrm{Cl}: 1.13-3.69)$. Higher second trimester $\mathrm{PM}_{2.5}$ exposure also was associated with increased depression at 12 months postpartum $(\mathrm{OR}=1.56,95 \% \mathrm{Cl}: 1.01-2.42)$. The effect for second trimester $\mathrm{PM}_{10}$ was similar and was borderline significant $(\mathrm{OR}=1.58,95 \% \mathrm{Cl}: 0.97-2.56)$.

Conclusions: In a low-income cohort consisting of primarily Hispanic/Latina women in urban Los Angeles, we found that prenatal ambient air pollution, especially mid-pregnancy $\mathrm{NO}_{2}$ and $\mathrm{PM}_{2.5}$, increased the risk of depression at 12 months after childbirth. These results underscore the need to better understand the contribution of modifiable environmental risk factors during potentially critical exposure periods.
\end{abstract}

\footnotetext{
*Correspondence: bastain@usc.edu

${ }^{1}$ Department of Population and Public Health Sciences, USC Keck School

of Medicine, University of Southern California, 2001 N. Soto Street, M/C

9237, Los Angeles, CA 90032, USA

Full list of author information is available at the end of the article
}

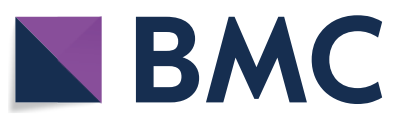

(c) The Author(s) 2021. Open Access This article is licensed under a Creative Commons Attribution 4.0 International License, which permits use, sharing, adaptation, distribution and reproduction in any medium or format, as long as you give appropriate credit to the original author(s) and the source, provide a link to the Creative Commons licence, and indicate if changes were made. The images or other third party material in this article are included in the article's Creative Commons licence, unless indicated otherwise in a credit line to the material. If material is not included in the article's Creative Commons licence and your intended use is not permitted by statutory regulation or exceeds the permitted use, you will need to obtain permission directly from the copyright holder. To view a copy of this licence, visit http://creativecommons.org/licenses/by/4.0/. The Creative Commons Public Domain Dedication waiver (http://creativeco mmons.org/publicdomain/zero/1.0/) applies to the data made available in this article, unless otherwise stated in a credit line to the data. 
Keywords: MADRES, Maternal health, Depression, Air pollution, Health disparities, Environment

\section{Background}

Depression is the leading cause of mental health-related morbidity worldwide, affecting approximately 300 million people annually [1]. While effective therapies are available, depression often requires chronic treatment with significant healthcare costs [2,3]. Depression is nearly twice as prevalent among women than men $[4,5]$. This difference is apparent early in adolescence and continues through midlife and beyond [6], suggesting that the reproductive years are particularly important for risk of depression in women.

Prevalence rates of depression are similar for Hispanic, non-Hispanic white and Black communities in the US [7]; however, reports of depressive symptoms have been higher in Hispanic populations than other groups [8]. The American Psychiatric Association has acknowledged that Hispanic communities have substantial barriers to accessing mental health services including limited knowledge about symptoms of mental health problems, cultural stigma associated with mental illness, lack of health insurance or inadequate coverage, and limited availability of culturally-competent and bilingual mental health care professionals [9].

Exposure to outdoor air pollution disproportionately impacts socio-economically disadvantaged populations and Hispanic and Black communities [10-13]. Increasing evidence suggests that pregnancy is a vulnerable window of exposure for later maternal health effects [14] including depression and other mental health disorders. Two recent studies showed that gestational exposure to particulate matter less than $2.5 \mu \mathrm{m}$ in aerodynamic diameter $\left[\mathrm{PM}_{2.5}\right]$ was associated with increased postpartum depressive symptoms $[15,16]$. In particular, exposure during mid-pregnancy-a period characterized by rapid rises in cardiac output, maternal blood volume, heart rate and pulmonary circulation necessary to maintain sufficient blood supply to the developing fetus [17] was shown to be associated with increased postpartum anhedonia symptoms at 6 or 12 months after childbirth particularly among Black women [15]. While there are multiple established biological and psychosocial risk factors for depression $[18,19]$, identifying potentially modifiable environmental risk factors to protect vulnerable populations is an urgent public health priority.

In this study, we examined whether higher concentrations of ambient air pollutants (including nitrogen dioxide $\left[\mathrm{NO}_{2}\right]$, ozone $\left[\mathrm{O}_{3}\right], \mathrm{PM}_{2.5}$ and $\mathrm{PM}_{10}$ ), during pregnancy were associated with increased depression at 12 months after childbirth in the MADRES cohort.

\section{Methods \\ Study design overview}

The MADRES cohort is an ongoing prospective pregnancy cohort that recruited over 800 predominantly lowincome Hispanic/Latina women at community health prenatal care providers in Los Angeles, CA between 2015 and 2020. The protocol, study design and detailed study procedures for the MADRES cohort are described elsewhere [20]. Briefly, prenatal data were collected during each trimester by interviewer-administered questionnaires in English or Spanish on the phone or in person. Follow-up of mothers and infants through 12 months postpartum consisted of a series of five phone questionnaires and in-person visits.

The full study protocol was approved by the University of Southern California Institutional Review Board and informed consent and HIPAA authorization for medical records abstraction were obtained prior to participation by bilingual MADRES staff members.

\section{Participants}

Study inclusion criteria for the MADRES cohort included $<30$ weeks gestation, singleton pregnancy, $\geq 18$ years old, and English or Spanish speaking. Study exclusions included current incarceration, HIV positive status and any cognitive or physical disability that would prevent participation in study procedures or providing informed consent. The consort diagram illustrating data available for this analysis is shown in Fig. 1. Participants in this sample were similar to the overall cohort (see Supplemental Table 1). The final sample included 180 participants who had completed the questionnaire at 12 months, were not pregnant, had key covariate information during pregnancy and had available prenatal ambient air pollution assignments for at least one pollutant.

\section{Depression outcome assessment Center for epidemiological studies-depression (CES-D) scale} The CES-D is a widely-used, validated 20-item instrument that was developed for use in epidemiological studies for assessing depressive symptoms experienced within the past week [21]. Prior studies have shown stability of CES-D scores in the first year postpartum and linkages with diagnosis of depression [22, 23]. Items cover multiple symptom clusters including depressed mood, loss of interest, feelings of guilt and worthlessness, psychomotor dysfunction, loss of appetite, and sleep disturbance. Scores range from 0 to 60 and scores 16 or above indicate risk for clinical depression [24]. The CES-D is a 


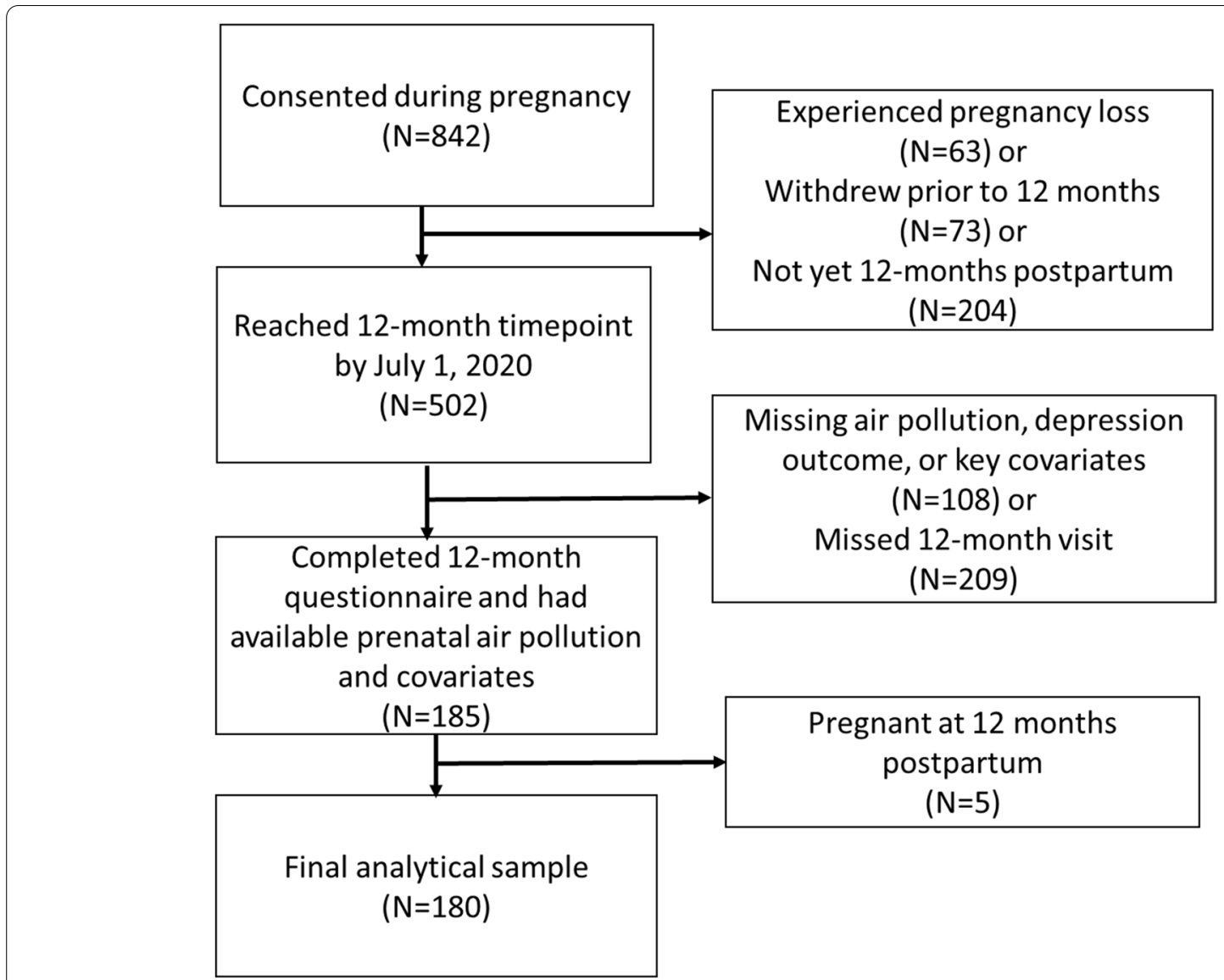

Fig. 1 Consort Diagram Illustrating Data Availability

reliable measure for evaluating depressive symptoms among women and men, Hispanic and non-Hispanic populations, and across age groups [21, 25, 26]. We classified a participant as depressed using the recommended cutoff of 16 or above, which is suggestive of clinical depression [21].

Previous history of depression was defined as depression diagnosis or history of antidepressant medication documented on the prenatal medical record.

\section{Ambient air pollution exposure assessment Residential address timelines}

Residential address history and occupancy dates from 1 year prior to conception through the third trimester of pregnancy were completed at home by study participants prior to the third trimester visit and then subsequently discussed with study staff to ensure data were captured accurately. Prospective address collection occurred at each follow-up study timepoint to capture residential mobility. Addresses were geocoded and daily residential timelines were assembled for each participant.

\section{Ambient air pollution}

Daily estimates of $\mathrm{NO}_{2}, \mathrm{O}_{3}, \mathrm{PM}_{2.5}$ and $\mathrm{PM}_{10}$ were assigned to the locations for the gestational time periods relevant for each study participant, using inversedistance-squared weighted spatial interpolation from ambient air quality monitoring data (U.S. EPA Air Quality System). Southern California has one of the densest monitoring networks in the US. The average number of monitors used in estimating concentrations at each residential location in our study was 3.97 for $\mathrm{NO}_{2}$ and $\mathrm{O}_{3}$ (range 2.04-4.00), 3.98 for $\mathrm{PM}_{2.5}$ (range (2.20-4.00) and 3.83 for $\mathrm{PM}_{10}$ (range 1.37-4.00). The spatial distribution of $\mathrm{NO}_{2}$ monitors in the monitoring network in Los Angeles overlayed on MADRES participant addresses at study enrollment is depicted in Supplement Fig. 1. We calculated average pollutant concentrations for each participant by trimester and across pregnancy.

\section{Daily temperature}

Daily temperature was calculated as the average of daily maximum and minimum temperatures extracted from a 
high-resolution $(4 \mathrm{~km} \times 4 \mathrm{~km})$ gridded surface meteorological dataset developed by Abatzoglou [27].

\section{Covariates}

A wide range of data were collected via intervieweradministered questionnaires, including preconception personal and family health history, pregnancy history, proxy measures of acculturation and demographic information. Questionnaire data on possible indoor air pollution sources, mode of travel and commuting time; housing characteristics; and history of tobacco smoke exposure were also collected. Prenatal medical records and birth records were abstracted at participating clinic sites and delivery hospitals for medication use during pregnancy, prenatal health history, delivery outcomes, and birth complications.

\section{Statistical methods \\ Descriptive and univariate analyses}

We summarized the distributions of each pollutant by trimester and over the entire pregnancy and calculated Spearman correlation coefficients to examine their correlations. We fitted unadjusted logistic regression models to explore relationships between depression and key demographic characteristics and maternal health conditions. We also examined differences between "depressed" and "not depressed" participants at 12 months using: independent $\mathrm{t}$-tests for normally-distributed continuous variables, Wilcoxon Mann-Whitney tests for nonnormally distributed variables, and Pearson's Chi-Square tests for categorical variables (or Fisher's Exact test if cell counts $<5$ ).

\section{Multivariable logistic regression}

We fitted multivariable logistic regression models to evaluate associations between trimester-specific and pregnancy average exposures and depression at 12 months postpartum. We considered a wide range of potential confounders identified a priori using Directed Acyclic Graphs (DAGs) that could be associated with both exposure and outcome including history of depression or antidepressant medication use, proxy measures of acculturation (language preference, nativity, years living in the US), demographic information (age, race, ethnicity, household income, education) and housing characteristics (air conditioning use, opening of windows, building or residence type and age). We also evaluated effects of indoor air pollution sources (cooking frequency and duration, gas stove usage); mode of travel and commuting time to reduce exposure measurement error; history of tobacco smoke exposure (lifetime, prenatal and secondhand); and personal and family health history, pregnancy history (e.g., parity, gestational age at birth, delivery type, pregnancy or birth complications).

We evaluated each of these potential covariates for confounding and included them in our final models if they were known or hypothesized to be associated with both exposure and outcome (age, ethnicity, nativity, household income, education, previous history of depression diagnosis, air conditioning use), if they resulted in greater than a 10\% change in the exposure effect estimates (average temperature), or if they were a study design variable that could account for unmeasured residual confounding by socioeconomic factors (study recruitment site). We parameterized the covariates included in the models as follows: maternal age at consent (continuous, in years); average temperature over the exposure averaging period (continuous, in degrees Celsius); recruitment site (indicators for recruitment site locations); maternal ethnicity and nativity (non-Hispanic; US born Hispanic; foreign born Hispanic-Mexico; foreign born Hispanic-other); maternal income (less than $\$ 15,000 ; \$ 15,000-\$ 29,999$; $\$ 30,000-\$ 49,999 ; \quad \$ 50,000-\$ 99,999 ; \$ 100,000+$; don't know); air conditioning use during pregnancy (yes/ no); depression diagnosis on medical record (yes/not recorded); and maternal education level (less than 12th grade; completed grade 12; some college or technical school; completed 4 years of college; some graduate training after college).

Participants with available data for any of the ambient pollutants and depression outcome at 12 months were included. Missing values for any of the categorical covariates were included in the multivariable models with missing indicators. We accounted for small sample bias in maximum likelihood estimation, by fitting logistic regression models with and without Firth's correction method for penalized likelihood [28, 29]. Exposure effect estimates were scaled to one standard deviation of exposure to each trimester-specific or pregnancy-average pollutant. We also conducted sensitivity analyses to determine whether (1) previous history of depression influenced our estimates; (2) our final model estimates were sensitive to residual confounding by population-level (census tract) socioeconomic and vulnerability factors not accounted for by individual level covariates; and (3) our results were influenced by annual average postpartum (birth to 12 months postpartum) air pollution levels. All analyses assumed a two-sided alternative hypothesis, an alpha level of 0.05 and were conducted using SAS Version 9.4.

\section{Results}

Demographic, maternal health characteristics and delivery outcomes are presented in Table 1. Participants in this sample were on average 29.8 years of age at study entry ( $\mathrm{SD}=6.0$ years). The majority of 
Table 1 Demographic characteristics, maternal health conditions and predictors of maternal depression at 12 months postpartum

\begin{tabular}{|c|c|c|c|c|c|}
\hline Characteristic & $\mathrm{N}$ & Mean (SD), \% & OR & $95 \% \mathrm{C}$ & \\
\hline Age at Study Entry (Years) & 180 & $29.8(6.0)$ & 1.00 & 0.94 & 1.07 \\
\hline \multicolumn{6}{|l|}{ Race and Ethnicity } \\
\hline Hispanic & 143 & $79.4 \%$ & -- REF -- & & \\
\hline Black & 8 & $4.4 \%$ & 1.83 & 0.35 & 9.68 \\
\hline Non-Hispanic White & 21 & $11.7 \%$ & 0.92 & 0.25 & 3.38 \\
\hline Multiracial & 2 & $1.1 \%$ & 5.50 & 0.33 & 91.26 \\
\hline Other & 5 & $2.8 \%$ & 1.38 & 0.15 & 12.89 \\
\hline Missing & 1 & $0.6 \%$ & & & \\
\hline \multicolumn{6}{|l|}{ Ethnicity and Nativity } \\
\hline US-Born Hispanic & 64 & $37.40 \%$ & -- REF -- & & \\
\hline Foreign-Born Hispanic & 71 & $41.50 \%$ & 1.83 & 0.68 & 4.91 \\
\hline Non-Hispanic & 36 & $21.10 \%$ & 1.97 & 0.63 & 6.14 \\
\hline Missing & 9 & $5.00 \%$ & & & \\
\hline \multicolumn{6}{|c|}{ Annual Household Income at Study Entry } \\
\hline Less than $\$ 15,000$ & 40 & $22.2 \%$ & -- REF -- & & \\
\hline$\$ 15,000$ to $\$ 29,999$ & 51 & $28.3 \%$ & 1.01 & 0.34 & 3.00 \\
\hline$\$ 30,000$ to $\$ 49,999$ & 22 & $12.2 \%$ & 0.74 & 0.17 & 3.22 \\
\hline$\$ 50,000$ to $\$ 99,999$ & 12 & $6.7 \%$ & 0.43 & 0.05 & 3.88 \\
\hline$\$ 100,000$ or more & 16 & $8.9 \%$ & 1.09 & 0.24 & 4.86 \\
\hline Don't Know & 38 & $21.1 \%$ & 0.88 & 0.27 & 2.92 \\
\hline Missing & 1 & $0.6 \%$ & & & \\
\hline \multicolumn{6}{|c|}{ Educational Attainment at Study Entry } \\
\hline$<12$ th Grade & 52 & $28.9 \%$ & -- REF -- & & \\
\hline Completed 12th Grade & 42 & $23.3 \%$ & 1.53 & 0.47 & 4.97 \\
\hline Some College or Technical School & 43 & $23.9 \%$ & 2.32 & 0.77 & 7.03 \\
\hline Completed College & 24 & $13.3 \%$ & 0.33 & 0.04 & 2.94 \\
\hline Some Graduate Training & 18 & $10.0 \%$ & 2.95 & 0.77 & 11.23 \\
\hline Missing & 1 & $0.6 \%$ & & & \\
\hline \multicolumn{6}{|l|}{ Marital Status } \\
\hline Never married, single & 31 & $17.2 \%$ & -- REF -- & & \\
\hline Married & 60 & $33.3 \%$ & 1.19 & 0.34 & 4.23 \\
\hline Living together & 71 & $39.4 \%$ & 1.51 & 0.45 & 5.07 \\
\hline Divorced or separated & 5 & $2.8 \%$ & 1.69 & 0.15 & 19.16 \\
\hline Missing & 13 & $7.2 \%$ & & & \\
\hline \multicolumn{6}{|l|}{ Pre-Pregnancy BMI Category } \\
\hline Normal & 46 & $25.6 \%$ & -- REF -- & & \\
\hline Underweight & 2 & $1.1 \%$ & 3.60 & 0.21 & 62.81 \\
\hline Overweight & 67 & $37.2 \%$ & 0.42 & 0.15 & 1.20 \\
\hline Obese & 65 & $36.1 \%$ & 0.73 & 0.28 & 1.91 \\
\hline \multicolumn{6}{|l|}{ Parity } \\
\hline 1st born & 65 & $36.1 \%$ & -- REF -- & & \\
\hline 2nd born & 48 & $26.7 \%$ & 0.98 & 0.36 & 2.66 \\
\hline 3rd born or more & 58 & $32.2 \%$ & 0.79 & 0.29 & 2.11 \\
\hline Missing & 9 & $5.0 \%$ & & & \\
\hline \multicolumn{6}{|l|}{ Mode of Delivery } \\
\hline Vaginal & 132 & $73.3 \%$ & -- REF -- & & \\
\hline Planned C-Section & 22 & $12.2 \%$ & 1.00 & 0.31 & 3.22 \\
\hline Unplanned/Emergency C-Section & 26 & $14.4 \%$ & 0.18 & 0.02 & 1.39 \\
\hline
\end{tabular}


Table 1 (continued)

\begin{tabular}{|c|c|c|c|c|c|}
\hline Characteristic & $\mathbf{N}$ & Mean (SD), \% & OR & $95 \% \mathrm{C}$ & \\
\hline \multicolumn{6}{|l|}{ Gestational Age at Delivery } \\
\hline Preterm (<37 weeks) & 22 & $12.2 \%$ & 0.43 & 0.09 & 2.02 \\
\hline Early Term (37 weeks-38 weeks 6/7 days) & 47 & $26.1 \%$ & 0.63 & 0.23 & 1.72 \\
\hline Full Term (39 weeks-40 weeks 6/7 days) & 96 & $53.3 \%$ & -- REF -- & & \\
\hline Late Term or Post Term ( $\geq 41$ weeks & 15 & $8.3 \%$ & 1.08 & 0.28 & 4.24 \\
\hline \multicolumn{6}{|l|}{ IOM Weight Gain Recommendations } \\
\hline Adequate & 54 & $30.0 \%$ & -- REF -- & & \\
\hline Excessive & 74 & $41.1 \%$ & 1.43 & 0.53 & 3.87 \\
\hline Insufficient & 34 & $18.9 \%$ & 0.90 & 0.24 & 3.32 \\
\hline Missing & 18 & $10.0 \%$ & & & \\
\hline \multicolumn{6}{|l|}{ Hypertensive Disorders } \\
\hline Normotensive & 147 & $81.7 \%$ & -- REF -- & & \\
\hline Hypertensive & 32 & $17.8 \%$ & 0.70 & 0.23 & 2.16 \\
\hline Missing & 1 & $0.6 \%$ & & & \\
\hline \multicolumn{6}{|l|}{ Diabetic Disorders } \\
\hline Normal & 118 & $65.6 \%$ & -- REF -- & & \\
\hline Glucose Intolerant & 35 & $19.4 \%$ & 0.69 & 0.24 & 1.97 \\
\hline Gestational Diabetes (GDM) ${ }^{\mathrm{a}}$ & 18 & $10.0 \%$ & - & - & - \\
\hline Chronic Diabetes & 8 & $4.4 \%$ & 0.59 & 0.07 & 5.04 \\
\hline Missing & 1 & $0.6 \%$ & & & \\
\hline \multicolumn{6}{|c|}{ Depression Diagnosis or Antidepressant Medication } \\
\hline No & 159 & $88.3 \%$ & -- REF -- & & \\
\hline Yes & 21 & $11.7 \%$ & 3.11 & 1.13 & 8.57 \\
\hline
\end{tabular}

${ }^{\text {a }}$ All participants with GDM scored $<16$ on CES-D

participants self-identified as Hispanic (79\%) and 39\% of participants were born outside of the United States. Most participants reported being married or living together with a partner (73\%). Fifty percent reported annual household income less than $\$ 30,000$ and 52\% of participants had at most a 12th grade education. Twenty-one women (12\%) had a previous history of depression.

There were a few demographic differences between this analytic sample of 180 women and the full cohort of 842 recruited women (Supplemental Table 1). The participants in this sample were slightly older at study entry compared to the full cohort (mean age 29.8 years versus 28.4 years). There were modest differences in socioeconomic status with respect to maternal educational attainment and household income level, with the current analytic sample having a higher proportion of college graduates or above $(23.3 \%$ versus $14.1 \%$ overall) and a higher proportion of participants reporting household income greater than $\$ 50,000$ per year (15.6\% versus $9.2 \%$ overall) reported household income on average. However, there are a greater percentage of missing data in the overall cohort relative to the analytic sample for these characteristics. In addition, 11.7\% of the analytical sample had a documented diagnosis of depression or antidepressant medication use documented on their medical record compared to $7.0 \%$ in the overall cohort.

Twenty-nine participants reported symptoms on the CES-D scale consistent with depression (score of $\geq 16$ ). The distribution of scores on the CES-D is shown in Supplemental Fig. 2. We examined the relationship of depression at 12 months postpartum with multiple demographic characteristics and maternal health conditions and found the only significant predictor of maternal depression at 12 months was a previous history of depression (OR $=3.11,95 \%$ CI: 1.13-8.57) (Table 1). We saw suggestive differences by nativity among Hispanic participants. Relative to US-Born Hispanic participants, foreign-born Hispanic participants had higher odds of depression $(\mathrm{OR}=1.83,95 \% \mathrm{CI}$ 0.68-4.97).

Average daily ambient pollutant $\left(\mathrm{NO}_{2}, \mathrm{O}_{3}, \mathrm{PM}_{2.5}\right.$, and $\left.\mathrm{PM}_{10}\right)$ concentrations over each trimester and across pregnancy are shown in Table 2. Across pregnancy, average daily $\mathrm{NO}_{2}$ concentrations were $17.0 \mathrm{ppb}$ $(\mathrm{SD}=2.7 \mathrm{ppb}), \quad \mathrm{O}_{3} \quad$ concentrations were $26.1 \mathrm{ppb}$ $(\mathrm{SD}=2.7 \mathrm{ppb}), \quad \mathrm{PM}_{2.5}$ concentrations were $12.2 \mu \mathrm{g} / \mathrm{m}^{3}$ 
Table 2 Ambient pollutant concentrations over four prenatal averaging periods

\begin{tabular}{|c|c|c|c|c|c|c|c|c|}
\hline \multirow[t]{2}{*}{ Pollutant } & \multicolumn{2}{|c|}{ 1st trimester } & \multicolumn{2}{|c|}{ 2nd trimester } & \multicolumn{2}{|c|}{ 3rd trimester } & \multicolumn{2}{|c|}{ Pregnancy average } \\
\hline & Mean & SD & Mean & SD & Mean & SD & Mean & SD \\
\hline $\mathrm{NO}_{2}(\mathrm{ppb})$ & 16.2 & 5.9 & 17.4 & 5.2 & 17.4 & 5.7 & 17.0 & 2.7 \\
\hline $\mathrm{O}_{3}(\mathrm{ppb})$ & 27.3 & 6.2 & 25.7 & 5.9 & 25.4 & 6.8 & 26.1 & 2.7 \\
\hline $\mathrm{PM}_{2.5}\left(\mu \mathrm{g} / \mathrm{m}^{3}\right)$ & 12.3 & 2.0 & 12.4 & 2.0 & 12.1 & 2.7 & 12.2 & 1.1 \\
\hline $\mathrm{PM}_{10}\left(\mu \mathrm{g} / \mathrm{m}^{3}\right)$ & 31.2 & 5.1 & 31.0 & 5.9 & 30.0 & 6.1 & 30.8 & 3.7 \\
\hline
\end{tabular}

$\left(\mathrm{SD}=1.1 \mu \mathrm{g} / \mathrm{m}^{3}\right)$, and $\mathrm{PM}_{10}$ concentrations were $30.9 \mu \mathrm{g} /$ $\mathrm{m}^{3}\left(\mathrm{SD}=3.8 \mu \mathrm{g} / \mathrm{m}^{3}\right)$.

Ozone $\left(\mathrm{O}_{3}\right)$ and $\mathrm{NO}_{2}$ showed significant negative correlations across each of the exposure averaging periods (e.g., 2nd trimester $r=-0.86, p<0.0001$ ). $\mathrm{PM}_{2.5}, \mathrm{PM}_{10}$ and $\mathrm{NO}_{2}$ were positively correlated across each of the exposure averaging periods, although the correlations were strongest between $\mathrm{PM}_{10}$ and $\mathrm{PM}_{2.5}$ concentrations (e.g., 2nd trimester $r=0.87, p<0.0001)$. Within pollutant, correlations across trimesters varied with generally positive correlations seen between 1st and 2nd trimesters and negative correlations between 1st and 3rd trimesters (see Supplemental Fig. 3).

Table 3 shows unadjusted and adjusted odds ratios for each ambient pollutant for trimester-specific and average pregnancy models. Table 3 also shows each adjusted model with Firth's method applied to account for small sample bias for maximum likelihood estimation.

We found that higher second trimester ambient $\mathrm{NO}_{2}$ was associated with increased depression at 12 months in unadjusted models ( $\mathrm{OR}=1.82,95 \% \mathrm{CI}$ : 1.22-2.73). In adjusted models, we found a 2.6 fold increased odds of depression at 12 months postpartum associated with second trimester $\mathrm{NO}_{2}$ exposure $(\mathrm{OR}=2.63,95 \% \mathrm{CI}$ : 1.41-4.89). When we applied Firth's method, the effect estimate was mildly attenuated $(\mathrm{OR}=2.22,95 \% \mathrm{CI}$ : 1.28-3.85), but remained statistically significant. We also found significantly increased odds of depression associated with pregnancy-average $\mathrm{NO}_{2}(\mathrm{OR}=2.04,95 \% \mathrm{CI}$ : 1.13-3.69) in adjusted models. Neither first nor third trimester $\mathrm{NO}_{2}$ concentrations were associated with depression at 12 months.

Table 3 Association of prenatal ambient air pollutants with maternal depression at 12 months postpartum

\begin{tabular}{|c|c|c|c|c|c|c|c|}
\hline \multirow[t]{2}{*}{ Pollutant } & \multirow[t]{2}{*}{ Exposure Averaging Period } & \multicolumn{2}{|c|}{ Model 1: Unadjusted } & \multicolumn{2}{|c|}{ Model 2: Adjusted ${ }^{b}$} & \multicolumn{2}{|c|}{$\begin{array}{l}\text { Model 3: Adjusted }{ }^{\mathrm{b}} \text { with } \\
\text { Firth's Correction }\end{array}$} \\
\hline & & $\mathbf{N}$ & $\mathrm{OR}^{\mathrm{a}}(95 \% \mathrm{Cl})$ & $\mathbf{N}$ & OR $(95 \% \mathrm{Cl})$ & $\mathrm{N}$ & OR $(95 \% \mathrm{CI})$ \\
\hline \multirow[t]{4}{*}{$\mathrm{NO}_{2}(\mathrm{ppb})$} & Trimester 1 & 179 & $1.02(0.68,1.53)$ & 179 & $1.29(0.70,2.40)$ & 179 & $1.24(0.72,2.14)$ \\
\hline & Trimester 2 & 180 & $1.82(1.22,2.73)^{* *}$ & 180 & $2.63(1.41,4.89)^{* *}$ & 180 & $2.22(1.28,3.85)^{* *}$ \\
\hline & Trimester 3 & 179 & $1.03(0.69,1.53)$ & 179 & $0.91(0.55,1.49)$ & 179 & $0.92(0.59,1.44)$ \\
\hline & Across Pregnancy & 180 & $1.58(1.05,2.37)^{*}$ & 180 & $2.04(1.13,3.69)^{*}$ & 180 & $1.82(1.08,3.07)^{*}$ \\
\hline \multirow[t]{4}{*}{$\mathrm{O}_{3}(\mathrm{ppb})$} & Trimester 1 & 179 & $0.89(0.60,1.33)$ & 179 & $0.60(0.31,1.16)$ & 179 & $0.65(0.37,1.16)$ \\
\hline & Trimester 2 & 180 & $0.75(0.51,1.12)$ & 180 & $0.68(0.35,1.32)$ & 180 & $0.73(0.40,1.31)$ \\
\hline & Trimester 3 & 179 & $1.14(0.76,1.70)$ & 179 & $1.48(0.84,2.63)$ & 179 & $1.40(0.84,2.35)$ \\
\hline & Across Pregnancy & 180 & $0.87(0.57,1.32)$ & 180 & $0.88(0.53,1.47)$ & 180 & $0.90(0.57,1.45)$ \\
\hline \multirow[t]{4}{*}{$\mathrm{PM}_{2.5}\left(\mu \mathrm{g} / \mathrm{m}^{3}\right)$} & Trimester 1 & 180 & $0.79(0.52,1.20)$ & 180 & $0.80(0.47,1.35)$ & 180 & $0.86(0.54,1.36)$ \\
\hline & Trimester 2 & 180 & $1.40(0.95,2.06)$ & 180 & $1.56(1.01,2.42)^{*}$ & 180 & $1.47(0.98,2.19)$ \\
\hline & Trimester 3 & 179 & $0.94(0.63,1.41)$ & 179 & $0.93(0.57,1.51)$ & 179 & $0.95(0.61,1.47)$ \\
\hline & Across Pregnancy & 180 & $1.11(0.75,1.64)$ & 180 & $1.33(0.83,2.15)$ & 180 & $1.28(0.82,1.99)$ \\
\hline \multirow[t]{4}{*}{$\mathrm{PM}_{10}\left(\mu \mathrm{g} / \mathrm{m}^{3}\right)$} & Trimester 1 & 179 & $0.88(0.59,1.31)$ & 179 & $0.69(0.37,1.28)$ & 179 & $0.76(0.44,1.30)$ \\
\hline & Trimester 2 & 180 & $1.34(0.92,1.97)$ & 180 & $1.58(0.97,2.56)$ & 180 & $1.46(0.94,2.28)$ \\
\hline & Trimester 3 & 179 & $1.03(0.69,1.53)$ & 179 & $1.02(0.58,1.80)$ & 179 & $1.02(0.61,1.70)$ \\
\hline & Across Pregnancy & 180 & $1.17(0.79,1.73)$ & 180 & $1.27(0.80,2.04)$ & 180 & $1.22(0.79,1.88)$ \\
\hline
\end{tabular}

${ }^{*} p<0.05 ;{ }^{* *} p<0.01$

${ }^{\text {a }}$ All odds ratios (OR) are scaled to one SD in exposure over the averaging period for each pollutant

${ }^{b}$ Adjusted for recruitment site, maternal age, ethnicity by nativity, household income, education, air conditioning use during pregnancy, previous history of depression, and average temperature over the exposure averaging period 
We found no significant associations between prenatal ambient ozone concentrations and depression at 12 months postpartum. For example, second trimester $\mathrm{O}_{3}$ was inversely associated with depression at 12 months, although this relationship was not significant $(\mathrm{OR}=0.68$, 95\% CI: 0.35-1.32).

Similar to our findings for second trimester $\mathrm{NO}_{2}$ exposure, we found that higher second trimester $\mathrm{PM}_{2.5}$ exposure was associated with increased depression at 12 months postpartum in the fully adjusted model $(\mathrm{OR}=1.56,95 \%$ CI: 1.01-2.42). The effect estimate was slightly attenuated with Firth's correction $(\mathrm{OR}=1.47$, 95\% CI: 0.98-2.10) and the association remained marginally significant. Pregnancy average $\mathrm{PM}_{2.5}$ exposure showed increased depression at 12 months $(\mathrm{OR}=1.33$, 95\% CI: 0.83-2.15), although this association did not reach statistical significance. Neither first nor third trimester $\mathrm{PM}_{2.5}$ concentrations were significantly associated with depression at 12 months.

While not statistically significant, the pattern of effects was similar for prenatal $\mathrm{PM}_{10}$. Both second trimester $\mathrm{PM}_{10}$ exposure $(\mathrm{OR}=1.58,95 \% \mathrm{CI}$ : 0.97-2.56) and pregnancy average exposure $(\mathrm{OR}=1.27,95 \% \mathrm{CI}$ : $0.80-2.04)$ were associated with increased odds of depression in adjusted models.

We examined whether a previous history of depression influenced our results. When we removed the 21 participants with a previous diagnosis of depression, results were similar (e.g., $\mathrm{OR}_{2 \text { nd trimester NO2 }}=2.35$, 95\% CI: $1.21-$ 4.55; data not shown). We also conducted a sensitivity analysis adjusting for CalEnviroScreen 3.0 [30] Population Characteristics scores (census tract-level population socioeconomic vulnerability) assigned to each participant's study enrollment address to investigate whether there could be residual confounding by neighborhood level socioeconomic factors not accounted for by adjustments for household income, maternal education and study recruitment site. We found our results to be robust to the addition of population vulnerability scores (e.g., $\mathrm{OR}_{2 \text { nd trimester NO2 }}=2.63,95 \% \mathrm{CI}: 1.40,4.93$; Supplemental Table 2). Similarly, when we adjusted for 12 month average postpartum pollutant levels, our results were largely

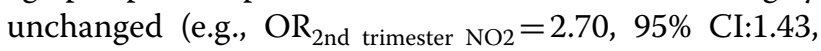
5.12; Supplemental Table 3).

\section{Discussion}

In a cohort of primarily low-income Hispanic/Latina women in Los Angeles, we found that exposure to prenatal ambient air pollution increased the risk of depression at 1 year after childbirth. Specifically, we found that second trimester and pregnancy average ambient $\mathrm{NO}_{2}$ levels were associated with greater than a two-fold increased risk of maternal depression at 12 months postpartum. We also found that second trimester $\mathrm{PM}_{2.5}$ concentrations were associated with increased depression at 12 months and the pattern of effects was similar for second trimester ambient $\mathrm{PM}_{10}$ concentrations.

We investigated whether the second trimester could be a proxy for the more proximate exposure period to the postpartum outcome measurement (e.g., exposure at $6-9$ months postpartum). While monthly pollutant levels tended to be correlated year to year, we found no evidence that $\mathrm{NO}_{2}$ exposure 6-9 months postpartum was associated with increased depression at 12 months (data not shown). Mounting evidence suggests that pregnancy is a vulnerable window of exposure for later maternal health effects [14]. Specifically, the second trimester could be a vulnerable period for both behavioral and physiological reasons. The second trimester is often characterized by decreased nausea, better sleep patterns and an increased energy level that may encourage greater time spent outdoors and result in higher ambient air pollution exposures. Moreover, beginning in the second trimester, the uterus expands and rapid rises in cardiac output, maternal blood volume, heart rate and pulmonary circulation occur that are necessary to maintain sufficient blood supply to the developing fetus [17].

Multiple human and animal studies have shown that air pollutants affect the brain through neuroinflammatory pathways [31-33]. The hypothalamic-pituitary-adrenal (HPA) axis can be activated by inhaled air pollution [34]. Prenatal $\mathrm{PM}_{10}$ and $\mathrm{PM}_{2.5}$ exposures have been linked to elevated maternal CRP and Il-6 levels [35, 36] and considerable evidence implicates these neuroinflammatory pathways in depression pathophysiology [37-42]. Pregnancy could be a specific vulnerable period for air pollution exposure effects on neuroinflammatory pathways as normal adaptive changes to the respiratory system, such as incremental gestational increases in respiration rate, minute ventilation and oxygen consumption, accommodate the metabolic demands of pregnancy and oxygen transfer across the placenta [17]. In addition, pregnant women have greater blood concentrations of inhaled compounds $[43,44]$, suggesting that pregnancy maybe a particularly vulnerable period for neurological effects of inhaled ambient air pollutants.

Our results are consistent with two recent studies that showed significant effects of $\mathrm{PM}_{2.5}$ exposure on maternal postpartum depression $[15,16]$. The first study in Boston, MA showed that second trimester $\mathrm{PM}_{2.5}$ exposure was associated with increased postpartum anhedonia symptoms at 6 or 12 months after childbirth and the effects were most pronounced among Black women [15]. They did not find significant effects within Hispanic women alone; however, the population of Hispanic women in the Boston study was largely born in the United States, with 
few women born in Mexico or of Mexican origin [16]. In contrast, nearly $50 \%$ of Hispanic women in the MADRES cohort were born outside of the U.S.-the majority of whom were born in Mexico (data not shown). The second study conducted in Mexico City found that a 5- $\mu \mathrm{g} /$ $\mathrm{m}^{3}$ increase in average prenatal $\mathrm{PM}_{2.5}$ exposure was associated with an $83 \%$ increase in risk of postpartum depression at 6 months. Among women without postpartum depression at 1 month, the same exposure showed a $158 \%$ increase in risk of late-onset postpartum depression at 6 months, suggesting that the detrimental impacts of prenatal $\mathrm{PM}_{2.5}$ exposure may not occur until several months following childbirth [16].

There is an increasing body of evidence documenting the impact of chronic air pollution exposure on major depression $[45,46]$. In a recent study of more than 150 million individuals in the US and Denmark, air pollution was associated with higher rates of major depression in both countries [47]. Long-term exposure to air pollution was also associated with increased depression in a study of middle-age and older adults in Spain [48] and in with new-onset depression among midlife and older women in the US [49].

It is increasingly acknowledged that exposure to air pollution disproportionately impacts health disparity populations [10-12]. In California, Black and Hispanic communities bear the highest burden of exposure to multiple environmental chemicals $[30,50]$. Approximately $80 \%$ of MADRES participants are Hispanic and about $50 \%$ were born outside of the US. Hispanic immigrant women have several unique risk factors for depression, including separation from family members and feelings of isolation [51]. While prevalence rates of depression are similar for U.S. Hispanic, non-Hispanic white and Black communities [7], reporting of depressive symptoms has been higher among Hispanic populations [8]. One reason suggested for the lower reported prevalence rate relative to reported symptoms is that the Hispanic community underutilizes mental health care services [52-54].

Our results suggested that foreign-born Hispanic participants had a higher risk of depression at 12 months than US-Born Hispanic participants and this increased risk varied by country of birth (data not shown). Multiple studies have shown that mental health status among immigrant populations declines with increasing acculturation [55-57]. Studies have also suggested that postpartum depression among US Hispanic immigrant populations is $40-60 \%$ compared to $\sim 14 \%$ of all new mothers in the US [58-60]. Premigration stress, low socioeconomic status, lack of social support, stressful life events, language barriers and difficulty adapting to a new culture may contribute to this disparity in postpartum depression [61].
This is the first study to our knowledge that has investigated the effects of multiple prenatal ambient pollutants on later maternal depression in a diverse population using daily estimates of ambient air pollutant exposures tied to time-resolved residential timelines, accounting for residential mobility. Our findings were robust to multiple sensitivity adjustments including population-level social vulnerabilities and postpartum air pollution levels. We used a validated depression scale with demonstrated reliability among women and men, Hispanic and non-Hispanic populations, and across age groups [21, 25, 26]. In addition, we were able to evaluate the impact of prior depression diagnosis and antidepressant medication usage as well as leverage considerable symptom data obtained from questionnaires. We found that removing women with a prior depression diagnosis did not impact our findings even though women with depression may be encouraged to increase their physical activity during pregnancy to reduce depressive symptoms [62-65] and increased physical activity could lead to increased exposure to ambient air pollution [66].

As with all studies, there were some limitations to our approach. Our findings may not be generalizable to all populations as the MADRES cohort draws its participants from prenatal health clinics in areas of high urban air pollution that serve women who have traditionally had lower access to health care-especially, mental health care-services. It has also been suggested that our measure of depression-the CES-D scale-may overestimate the number of true cases of depression [26]. However, we have no reason to assume the outcome misclassification would be related to air pollution exposure, suggesting that any bias would be toward the null. We also did not have information on whether our participants were diagnosed with postpartum depression, or whether those with a history of depression were undergoing treatment at 12 months. In fact, among the 21 women with a documented history of depression, only 7 women reported symptoms consistent with depression at 12 months, suggesting that the remaining women with a history of depression may have controlled their symptoms effectively with antidepressant medication or psychotherapy.

While retention in the MADRES cohort has remained high overall, participants are not always able to complete all study timepoints and therefore the available outcome follow-up data at 12 months was limited to a relatively small sample. We found modest differences in sociodemographic characteristics between the participants in this subsample and the overall cohort and therefore cannot indefinitely rule out whether characteristics related to participation could have influenced our results. We also investigated whether the women who missed the 12-month postpartum study visit had different patterns 
of prenatal exposure to ambient air pollutants from those who completed the visit. We found that the average prenatal pollutant concentrations were not significantly different for women who completed and did not complete this visit (data not shown) and this was unlikely to account for our findings.

While we did not have measurements of personal exposure to air pollution, we estimated exposure to ambient air pollution at each participant's home based on inverse distance weighting methods. These methods are likely to result in exposure measurement error, in part due to the fundamental assumption that participants' exposures occur primarily outdoors at the home. However, this error applies equally to depression cases and non-cases, suggesting that any bias would also be toward the null. Even with these limitations, our results were robust to multiple adjustments, and multiple correlated ambient pollutants exhibited similar effects on maternal depression at 12 months. Further investigations are needed to examine the underlying biological mechanisms at play and to explore specific mid-pregnancy windows of susceptibility to effects of air pollution on women's postpartum health.

\section{Conclusions}

We found compelling evidence that prenatal ambient air pollution exposure may have long-term impacts on maternal depression. These results underscore the need to better understand the contribution of modifiable environmental risk factors during susceptible periods, and have important implications for identification, prevention and treatment of depression in vulnerable women in the years following childbirth.

\section{Abbreviations \\ MADRES: Maternal And Developmental Risks from Environmental and Social Stressors cohort study; NHANES: National Health and Nutrition Examination Survey; HIPAA: Health Information Portability and Accountability Act; USC: University of Southern California; CES-D: Center for Epidemiological Studies- Depression Scale; $\mathrm{PM}_{2.5}$ : Particulate Matter less than $2.5 \mu \mathrm{m}$ in diameter; $\mathrm{PM}_{10}$ Particulate Matter less than $10 \mu \mathrm{m}$ in diameter; $\mathrm{NO}_{2}$ : Nitrogen dioxide; $\mathrm{O}_{3}$ : Ozone; HPA: Hypothalamic-pituitary-adrenal axis; GA: Gestational age; BMl: Body mass index.}

\section{Supplementary Information}

The online version contains supplementary material available at https://doi. org/10.1186/s12940-021-00807-x.

Additional file 1: Supplement Figure 1. Monitoring network density for nitrogen dioxide $\left(\mathrm{NO}_{2}\right)$ in Los Angeles, $\mathrm{CA}$.

Additional file 2: Supplement Figure 2. Distribution of Scores on the Center for Epidemologic Studies-Depression (CES-D) Scale at 12-Months Postpartum

Additional file 3: Supplement Figure 3. Spearman Correlations for each Ambient Pollutant by Trimester and Across Pregnancy.
Additional file 4: Supplement Table 1. Demographic characteristics in the full MADRES cohort and the current analytic sample. Supplement Table 2. Association of Prenatal Ambient Air Pollutants with Maternal Depression at 12 Months Postpartum, Additionally Adjusted for CalEnviroScreen Population Vulnerability Score. Supplement Table 3. Association of Prenatal Ambient Air Pollutants with Maternal Depression at 12 Months Postpartum, Additionally Adjusted for 12 Month Annual Average Postpartum Ambient Air Pollution.

\section{Acknowledgements}

We are indebted to the MADRES study families, nurses, midwives, physicians, and staff at each of our study sites for their cooperation and participation and especially to the members of the MADRES study team for their efforts to improve the health of underserved communities.

\section{Authors' contributions}

TMB led and conceptualized the cohort design, protocol development, questionnaire design, site recruitment, directed the study team and wrote the manuscript; TC managed and analyzed the data; RH led the exposure design, residential geocoding and geospatial analysis; $\mathrm{IH}$ analyzed data and contributed to editing and revisions; CTC contributed to data collection and manuscript editing; SFF contributed to questionnaire design and manuscript editing; IL, BG, DL, and NL provided clinical input and contributed to manuscript writing; SPE contributed to study design and manuscript editing; FL contributed to exposure assignments and exposure study design; CB led and conceptualized cohort design, protocol development, laboratory protocols, questionnaire design, outcome and exposure measurements. All authors read and approved the final manuscript and had no conflicts of interest to disclose.

\section{Funding}

This work was supported by the Maternal and Developmental Risks from Environmental and Social Stressors (MADRES) Center (grant \#s P50ES026086, 83615801-0, P50MD01570) funded by the National Institute of Environmental Health Sciences, the National Institute for Minority Health and Health Disparities and the Environmental Protection Agency; the Southern California Environmental Health Sciences Center (grant \# P30ES007048) funded by the National Institute of Environmental Health Sciences, and the Lifecourse Approach to Developmental Repercussions of Environmental Agents on Metabolic and Respiratory health (LA DREAMERs) (grant \#s UH3OD023287) funded by the National Institutes of Health Office of the Director ECHO Program. The funding agencies had no role in the design of the study, the collection, analysis, or interpretation of data or in the writing of the manuscript.

\section{Availability of data and materials}

The datasets used and/or analyzed during the current study are available from the corresponding author on reasonable request and after approval by the USC Institutional Review Board.

\section{Declarations}

\section{Ethics approval and consent to participate}

The full study protocol was approved by the University of Southern California Institutional Review Board and informed consent and HIPAA authorization for medical records abstraction were obtained prior to participation by bilingual MADRES staff members.

\section{Consent for publication}

Not applicable.

\section{Competing interests}

The authors declare that they have no competing interests.

\section{Author details}

'Department of Population and Public Health Sciences, USC Keck School of Medicine, University of Southern California, 2001 N. Soto Street, M/C 9237, Los Angeles, CA 90032, USA. ${ }^{2}$ Department of Obstetrics and Gynecology, University of Southern California, Los Angeles, USA. ${ }^{3}$ Department of Health Sciences, California State University, Northridge, USA. ${ }^{4}$ Eisner Health, Los Angeles, 
USA. ${ }^{5}$ Sonoma Technology, Inc, Petaluma, USA. ${ }^{6}$ Department of Psychiatry and Behavioral Sciences, University of Southern California, Los Angeles, USA.

Received: 16 March 2021 Accepted: 15 November 2021

Published online: 27 November 2021

\section{References}

1. Patel V, Chisholm D, Parikh R, et al. Addressing the burden of mental, neurological, and substance use disorders: key messages from Disease Control Priorities, 3rd edition. Lancet. 2016;387:1672-85.

2. Hardeveld F, Spijker J, De Graaf R, Nolen WA, Beekman AT. Prevalence and predictors of recurrence of major depressive disorder in the adult population. Acta Psychiatr Scand. 2010;122:184-91.

3. Greenberg PE, Fournier AA, Sisitsky T, Pike CT, Kessler RC. The economic burden of adults with major depressive disorder in the United States (2005 and 2010). J Clin Psychiatry. 2015;76:155-62.

4. Weissman MM, Bland RC, Canino GJ, et al. Cross-national epidemiology of major depression and bipolar disorder. JAMA. 1996;276:293-9.

5. Table 1.59B - Major Depressive Episode (MDE) in the past year among persons aged 18 or older, by gender and detailed age category: percentages, 2011 and 2012. 2011. https://www.samhsa.gov/data/sites/defau It/files/2k12MH DetTbls/2k12MH_DetTbls/HTML/NSDUH-MHDetTabsS ect1 peTabs2012.htm\#Tab1.59B. Accessed 28 Sept 2019

6. Burke KC, Burke JD Jr, Regier DA, Rae DS. Age at onset of selected mental disorders in five community populations. Arch Gen Psychiatry. 1990;47:511-8.

7. Prevalence of depression among adults aged 20 and over: United States, 2013-2016. 2018. https://www.cdc.gov/nchs/products/databriefs/db303. htm. Accessed 10 Oct 2019.

8. National health interview survey 2017. 2017. https://ftp.cdc.gov/pub/ Health_Statistics/NCHS/NHIS/SHS/2017_SHS_Table_A-7.pdf. Accessed 28 Sept 2019.

9. Mental health disparities: Hispanics and Latinos. 2017. https://www.psych iatry.org/File\%20Library/Psychiatrists/Cultural-Competency/MentalHealth-Disparities/Mental-Health-Facts-for-Hispanic-Latino.pdf. Accessed 28 Sept 2019

10. Woodruff TJ, Parker JD, Kyle AD, Schoendorf KC. Disparities in exposure to air pollution during pregnancy. Environ Health Perspect. 2003;111:942-6.

11. Miranda ML, Edwards SE, Keating MH, Paul CJ. Making the environmental justice grade: the relative burden of air pollution exposure in the United States. Int J Environ Res Public Health. 2011:8:1755-71.

12. Bell ML, Ebisu K. Environmental inequality in exposures to airborne particulate matter components in the United States. Environ Health Perspect. 2012:120:1699-704.

13. Cushing L, Morello-Frosch R, Wander M, Pastor M. The haves, the have-nots, and the health of everyone: the relationship between social inequality and environmental quality. Annu Rev Publ Health. 2015;36:193-209.

14. Koman PD, Hogan KA, Sampson N, et al. Examining joint effects of air pollution exposure and social determinants of health in defining "at-risk" populations under the clean air act: susceptibility of pregnant women to hypertensive disorders of pregnancy. World Med Health Policy. 2018:10:7-54

15. Sheffield PE, Speranza R, Chiu YM, et al. Association between particulate air pollution exposure during pregnancy and postpartum maternal psychological functioning. PLoS One. 2018;13:e0195267.

16. Niedzwiecki MM, Rosa MJ, Solano-Gonzalez M, et al. Particulate air pollution exposure during pregnancy and postpartum depression symptoms in women in Mexico city. Environ Int. 2020;134:105325.

17. Tan EK, Tan EL. Alterations in physiology and anatomy during pregnancy. Best Pract Res Clin Obstet Gynaecol. 2013;27:791-802.

18. Noble RE. Depression in women. Metabolism. 2005;54:49-52.

19. Fairthorne J, Hanley GE, Oberlander TF. Depressed women of low socioeconomic status have high numbers of physician visits in the year before pregnancy: implications for care. J Clin Med Res. 2018;10:516-22.

20. Bastain TM, Chavez T, Habre R, et al. Study design, protocol and profile of the maternal and developmental risks from environmental and social stressors (MADRES) pregnancy cohort: a prospective cohort study in predominantly low-income Hispanic women in urban Los Angeles. BMC Pregnancy Childbirth. 2019;19:189.

21. Radloff LS. The CES-D scale: a self-report depression scale for research in the general population. Appl Psychol Meas. 1977;1:385-401.

22. Beeghly M, Olson KL, Weinberg MK, Pierre SC, Downey N, Tronick EZ. Prevalence, stability, and socio-demographic correlates of depressive symptoms in Black mothers during the first 18 months postpartum. Matern Child Health J. 2003;7:157-68.

23. Beeghly M, Weinberg MK, Olson KL, Kernan H, Riley J, Tronick EZ. Stability and change in level of maternal depressive symptomatology during the first postpartum year. J Affect Disord. 2002;71:169-80.

24. Lewinsohn PM, Seeley JR, Roberts RE, Allen NB. Center for Epidemiologic Studies Depression Scale (CES-D) as a screening instrument for depression among community-residing older adults. Psychol Aging. 1997;12:277-87.

25. Knight RG, Williams S, McGee R, Olaman S. Psychometric properties of the Centre for Epidemiologic Studies Depression Scale (CES-D) in a sample of women in middle life. Behav Res Ther. 1997;35:373-80.

26. Roberts RE, Vernon SW, Rhoades HM. Effects of language and ethnic status on reliability and validity of the Center for Epidemiologic Studies-Depression Scale with psychiatric patients. J Nerv Ment Dis. 1989;177:581-92.

27. Abatzoglou JT. Development of gridded surface meteorological data for ecological applications and modelling. Int J Climatol. 2013:33:121-31.

28. Firth D. Bias reduction of maximum-likelihood-estimates. Biometrika. 1993;80:27-38.

29. van Smeden M, de Groot JAH, Moons KGM, et al. No rationale for 1 variable per 10 events criterion for binary logistic regression analysis. BMC Med Res Methodol. 2016;16(1):1-2.

30. CalEnviroScreen 3.0. California Environmental Protection Agency, 2017. http://oehha.ca.gov/calenviroscreen. Accessed 1 Feb 2021.

31. Cheng H, Saffari A, Sioutas C, Forman HJ, Morgan TE, Finch CE. Nanoscale particulate matter from urban traffic rapidly induces oxidative stress and inflammation in olfactory epithelium with concomitant effects on brain. Environ Health Perspect. 2016;124:1537-46.

32. Oppenheim HA, Lucero J, Guyot AC, et al. Exposure to vehicle emissions results in altered blood brain barrier permeability and expression of matrix metalloproteinases and tight junction proteins in mice. Part Fibre Toxicol. 2013;10:62.

33. Erickson MA, Dohi K, Banks WA. Neuroinflammation: a common pathway in CNS diseases as mediated at the blood-brain barrier. Neuroimmunomodulation. 2012;19:121-30.

34. Snow SJ, Henriquez AR, Costa DL, Kodavanti UP. Neuroendocrine regulation of air pollution health effects: emerging insights. Toxicol Sci. 2018;164:9-20

35. Lee PC, Talbott EO, Roberts JM, Catov JM, Sharma RK, Ritz B. Particulate air pollution exposure and $C$-reactive protein during early pregnancy. Epidemiology. 2011;22:524-31.

36. Buxton MA, Meraz-Cruz N, Sanchez BN, et al. Air pollution and inflammation: findings from concurrent repeated measures of systemic and reproductive tract cytokines during term pregnancy in Mexico City. Sci Total Environ. 2019:681:235-41.

37. Miller AH, Maletic $\mathrm{V}$, Raison CL. Inflammation and its discontents: the role of cytokines in the pathophysiology of major depression. Biol Psychiatry. 2009;65:732-41.

38. Hacimusalar Y, Esel E. Suggested biomarkers for major depressive disorder. Noro Psikiyatr Ars. 2018;55:280-90.

39. Muller N. Immunology of major depression. Neuroimmunomodulation. 2014:21:123-30

40. Kim YK, Na KS, Shin KH, Jung HY, Choi SH, Kim JB. Cytokine imbalance in the pathophysiology of major depressive disorder. Prog NeuroPsychopharmacol Biol Psychiatry. 2007;31:1044-53.

41. Kohler-Forsberg O, Buttenschon HN, Tansey KE, et al. Association between C-reactive protein (CRP) with depression symptom severity and specific depressive symptoms in major depression. Brain Behav Immun. 2017;62:344-50.

42. Jia Y, Liu L, Sheng C, et al. Increased serum levels of cortisol and inflammatory cytokines in people with depression. J Nerv Ment Dis. 2019;207:271-6. 
43. Brochu P, Bouchard M, Haddad S. Physiological daily inhalation rates for health risk assessment in overweight/obese children, adults, and elderly. Risk Anal. 2014;34:567-82.

44. Valcke M, Nong A, Krishnan K. Modeling the human kinetic adjustment factor for inhaled volatile organic chemicals: whole population approach versus distinct subpopulation approach. J Toxicol. 2012;2012:404329.

45. Gladka A, Rymaszewska J, Zatonski T. Impact of air pollution on depression and suicide. Int J Occup Med Environ Health. 2018;31:711-21.

46. Kim KN, Lim YH, Bae HJ, Kim M, Jung K, Hong YC. Long-term fine particulate matter exposure and major depressive disorder in a communitybased urban cohort. Environ Health Perspect. 2016;124:1547-53.

47. Khan A, Plana-Ripoll O, Antonsen S, et al. Environmental pollution is associated with increased risk of psychiatric disorders in the US and Denmark. PLoS Biol. 2019;17:e3000353.

48. Vert C, Sanchez-Benavides G, Martinez D, et al. Effect of long-term exposure to air pollution on anxiety and depression in adults: a cross-sectional study. Int J Hyg Environ Health. 2017;220:1074-80.

49. Kioumourtzoglou MA, Power MC, Hart JE, et al. The association between air pollution and onset of depression among middle-aged and older women. Am J Epidemiol. 2017:185:801-9.

50. OEHHA. Analysis of Calenvironscreen 2.0 scores and race/ethnicity. Sacramento: Office of Environmental Health Hazard Assessment; 2014

51. Shattell MM, Smith KM, Quinlan-Colwell A, Villalba JA. Factors contributing to depression in latinas of mexican origin residing in the United States: implications for nurses. J Am Psychiatr Nurses Assoc. 2008;14:193-204.

52. Lagomasino IT, Dwight-Johnson M, Miranda J, et al. Disparities in depression treatment for Latinos and site of care. Psychiatr Serv. 2005:56:1517-23.

53. Vega WA, Kolody B, Aguilar-Gaxiola S, Catalano R. Gaps in service utilization by Mexican Americans with mental health problems. Am J Psychiatry. 1999;156:928-34.

54. Hough RL, Landsverk JA, Karno M, et al. Utilization of health and mental health services by Los Angeles Mexican Americans and non-Hispanic whites. Arch Gen Psychiatry. 1987;44:702-9.

55. Breslau J, Aguilar-Gaxiola S, Borges G, et al. Mental disorders among English-speaking Mexican immigrants to the US compared to a national sample of Mexicans. Psychiatry Res. 2007;151:115-22.
56. Breslau J, Aguilar-Gaxiola S, Borges G, Kendler KS, Su M, Kessler RC. Risk for psychiatric disorder among immigrants and their US-born descendants: evidence from the National Comorbidity Survey Replication. J Nerv Ment Dis. 2007;195:189-95.

57. Hiott A, Grzywacz JG, Arcury TA, Quandt SA. Gender differences in anxiety and depression among immigrant Latinos. US: Educational Publishing Foundation; 2006. p. 137-46.

58. Lucero NB, Beckstrand RL, Callister LC, Sanchez Birkhead AC. Prevalence of postpartum depression among Hispanic immigrant women. J Am Acad Nurse Pract. 2012;24:726-34.

59. Shellman L, Beckstrand RL, Callister LC, Luthy KE, Freeborn D. Postpartum depression in immigrant Hispanic women: a comparative community sample. J Am Assoc Nurse Pract. 2014;26:488-97.

60. Wisner KL, Sit DK, McShea MC, et al. Onset timing, thoughts of self-harm, and diagnoses in postpartum women with screen-positive depression findings. JAMA Psychiatry. 2013;70:490-8.

61. Zelkowitz P, Schinazi J, Katofsky L, et al. Factors associated with depression in pregnant immigrant women. Transcult Psychiatry. 2004:41:445-64.

62. Farris SG, Abrantes AM, Uebelacker LA, Weinstock LM, Battle CL. Exercise as a nonpharmacological treatment for depression. Psychiat Ann. 2019;49:6-10

63. Stubbs B, Rosenbaum S, Vancampfort D, Ward PB, Schuch FB. Exercise improves cardiorespiratory fitness in people with depression: a metaanalysis of randomized control trials. J Affect Disord. 2016;190:249-53.

64. Schuch FB, Vancampfort D, Richards J, Rosenbaum S, Ward PB, Stubbs B. Exercise as a treatment for depression: a meta-analysis adjusting for publication bias. J Psychiatr Res. 2016;77:42-51.

65. Birsner ML, Gyamfi-Bannerman C. Physical activity and exercise during pregnancy and the postpartum period ACOG Committee opinion summary, number 804. Obstet Gynecol. 2020;135:E178-E88.

66. Tainio M, Andersen ZJ, Nieuwenhuijsen MJ, et al. Air pollution, physical activity and health: a mapping review of the evidence. Environ Int. 2021:147:105954.

\section{Publisher's Note}

Springer Nature remains neutral with regard to jurisdictional claims in published maps and institutional affiliations.
Ready to submit your research? Choose BMC and benefit from:

- fast, convenient online submission

- thorough peer review by experienced researchers in your field

- rapid publication on acceptance

- support for research data, including large and complex data types

- gold Open Access which fosters wider collaboration and increased citations

- maximum visibility for your research: over 100M website views per year

At BMC, research is always in progress.

Learn more biomedcentral.com/submissions 